\title{
Estimation of utility values from visual analog scale measures of health in patients undergoing cardiac surgery
}

This article was published in the following Dove Press journal:

ClinicoEconomics and Outcomes Research

10 January 2014

Number of times this article has been viewed

\author{
Lars Oddershede ${ }^{1,2}$ \\ Jan Jesper Andreasen ${ }^{\prime}$ \\ Lars Ehlers ${ }^{2}$
}

'Department of Cardiothoracic Surgery, Center for Cardiovascular Research, Aalborg University Hospital, Aalborg, Denmark; ${ }^{2}$ Danish Center for Healthcare Improvements, Faculty of Social Sciences and Faculty of Health Sciences, Aalborg University, Aalborg East, Denmark
Correspondence: Lars Oddershede Danish Center for Healthcare Improvements, Aalborg University, Fibigerstræde II, DK-9220 Aalborg East, Denmark

Tel +45 40609448

Email lars.oddershede@gmail.com
Introduction: In health economic evaluations, mapping can be used to estimate utility values from other health outcomes in order to calculate quality adjusted life-years. Currently, no methods exist to map visual analog scale (VAS) scores to utility values. This study aimed to develop and propose a statistical algorithm for mapping five dimensions of health, measured on VASs, to utility scores in patients suffering from cardiovascular disease.

Methods: Patients undergoing coronary artery bypass grafting at Aalborg University Hospital in Denmark were asked to score their health using the five VAS items (mobility, self-care, ability to perform usual activities, pain, and presence of anxiety or depression) and the EuroQol 5 Dimensions questionnaire. Regression analysis was used to estimate four mapping models from patients' age, sex, and the self-reported VAS scores. Prediction errors were compared between mapping models and on subsets of the observed utility scores. Agreement between predicted and observed values was assessed using Bland-Altman plots.

Results: Random effects generalized least squares (GLS) regression yielded the best results when quadratic terms of VAS scores were included. Mapping models fitted using the Tobit model and censored least absolute deviation regression did not appear superior to GLS regression. The mapping models were able to explain approximately $63 \%-65 \%$ of the variation in the observed utility scores. The mean absolute error of predictions increased as the observed utility values decreased.

Conclusion: We concluded that it was possible to predict utility scores from VAS scores of the five dimensions of health used in the EuroQol questionnaires. However, the use of the mapping model may be inappropriate in more severe conditions.

Keywords: coronary artery bypass grafts, mapping, cross-walk, quality of life, outcomes research

\section{Introduction}

In health economic evaluations, the recommended measure of health effects is quality adjusted life-years, which enables the comparison of interventions across disease areas. ${ }^{1,2}$ However, clinical trials are frequently initiated without including questionnaires measuring preference-based health-related quality of life. Instead, nonpreference-based measures of health are often utilized and this renders it difficult to estimate health state utility values. One solution that is gaining popularity is prediction of utility values from the nonpreference-based measures of health. This is frequently called mapping and the technique requires an algorithm based on the statistical association between the tools. ${ }^{3}$ Mapping techniques have been applied in more than a quarter of technology appraisals submitted to the National Institute of Clinical Excellence. ${ }^{4}$ Most mapping 
techniques predict the utility values from disease-specific questionnaires. ${ }^{3}$ However, sometimes health effects are merely measured using a visual analog scale (VAS) instead of disease-specific questionnaires. The VAS is one of the most frequently used methods for assessing pain intensity, ${ }^{5,6}$ and has also been applied in the assessment of depression, anxiety, and mobility. ${ }^{7,8}$ Currently no method has been developed for predicting utility scores from such VAS scores.

This study aimed to develop a mapping model to predict a single utility score from five VAS scores rating patients' mobility, self-care, ability to perform usual activities, pain, and anxiety and depression. Such a model may be applied to map the partial effect of reducing patients' pain measured on a VAS to utility scores, under the ceteris paribus assumption, ie, holding all other factors fixed.

We chose to estimate our mapping model by administering our questionnaire to patients undergoing coronary artery bypass grafting (CABG), for two reasons: 1) clinical trials investigating surgical interventions frequently use the VAS when assessing outcomes; and 2) patients undergoing $\mathrm{CABG}$ vary widely in the severity of their health conditions pre- and postoperatively. This heterogeneity in their responses makes them ideal respondents.

\section{Methods}

\section{Patients}

Data were prospectively collected between August 25, 2011 and May 25, 2013, from patients recruited from the cardiothoracic surgical ward at Aalborg University Hospital, Denmark. Eligible patients were more than 18 years of age, were able to read Danish, and had coronary artery disease requiring elective CABG. Approximately $250 \mathrm{CABG}$ procedures are performed at Aalborg University Hospital every year. We divided the dataset in two, by random sampling, such that $60 \%$ of the patients were included in the estimation sample and the remaining $40 \%$ of the patients were included in the validation sample.

\section{Questionnaires}

For the purpose of developing the mapping-model, all patients were asked to complete the three level version of the EuroQol 5 Dimensions questionnaire (EQ-5D) and to rate their perceived health today on five VAS items (patients' self-reported mobility, self-care, ability to perform usual activities, pain, and presence of anxiety or depression). Each VAS item was given an introductory title and a short statement representing "no problems" at $0 \mathrm{~mm}$ and a short statement representing "worst imaginable problems" at $100 \mathrm{~mm}$.
Patients were asked to fill out the EQ-5D as many as three times. The first time was prior to their admission, the second time was 5 days postsurgery, and the third time was upon the arrival for their follow-up visit at the outpatient clinic. Only patients seen at the outpatient clinic at Aalborg University Hospital were asked to fill out the third questionnaire. In the analyses, each questionnaire was treated as an independent measurement in order to obtain diversity in the severity of health states.

\section{Analyses}

For all mapping models, the dependent variable was the utility score calculated using the Danish time trade-off values. ${ }^{9}$ These values for the EQ-5D range from 1 to -0.624 where 1 indicates perfect health, 0 indicates death, and a value below zero is a health state perceived to be worse than death. We fitted two mapping-models using the $60 \%$ estimation sample. The first mapping model was fitted using age, sex, and the five VAS scores as explanatory variables. In the second mapping model, the squared terms of the five VAS scores were included. The squared terms were added in the second mapping model because the relationship between explanatory dimensions and utility scores may not be linear in nature. ${ }^{10,11}$ Although dimensions may not be additive, ${ }^{11,12}$ interaction terms were not considered as they may restrict the use of the mapping models to situations where all five VAS scores are measured. Excluding the interaction terms allows the mapping-models to be used in situations where only one or two of the VAS scores are measured. Both mapping models were initially fitted using random intercepts generalized least squares (GLS) models. Least squared estimation was chosen because of its straightforward interpretation and frequent use in mapping models. ${ }^{3}$ The random effects part was chosen to handle the fact that some patients had multiple observations. However, if least squared estimation is used in the presence of large proportions of subjects scoring utility values of 1 , the bounded nature of the utility value may result in implausible predictions outside of the existing range of the scale. ${ }^{3,13}$ In such situations, researchers have proposed using the Tobit model or censored least absolute deviation (CLAD) regression methods. ${ }^{3,14}$ If the proportion of patients at the upper ceiling is small the marginal coefficients from the random effects GLS should suffice. ${ }^{15}$ Nevertheless, to accommodate the possibility that the observed ceiling effect might reduce the performance of our random effects GLS models, random effects Tobit regression and CLAD regressions were also fitted. The random effects Tobit regression handles the bounded nature of the utility scores and may therefore be an appropriate alternative to least 
squares estimation. ${ }^{11,14,16}$ However, a random effects Tobit model will produce biased results when faced with heteroscedasticity or nonnormality. ${ }^{11,16}$ CLAD regression will produce consistent results even if faced with heteroscedasticity or nonnormality. ${ }^{17}$ As such, the CLAD regression may seem the optimal choice. However, the downside to a CLAD mapping model is that it is a median model. ${ }^{13}$ Typically, economic evaluations use health valuations based on mean models. To assess the performance of the mapping models, we calculated the root mean squared error (RMSE) and mean absolute error (MAE) to compare the models. ${ }^{3,13}$ Errors were subsequently reported for the following subsets of observed utility values: utility $<0 ; 0 \leq$ utility $<0.25 ; 0.25 \leq$ utility $<0.5 ; 0.5 \leq$ utility $<0.75 ; 0.75 \leq$ utility $\leq 1$.

We predicted the utility values in the validation sample using the second (full) random effects GLS mapping model to assess if the estimates were reliable. For both the estimation sample and the validation sample, Bland-Altman plots were used to assess agreement between observed and predicted values. All statistical analyses were performed in Stata version 12.1 (StataCorp LP, College Station, TX, USA). The CLAD regression was performed using user-written programs for Stata. ${ }^{18}$ The questionnaires were entered once in EpiData version 3.1 (freeware product by EpiData Association, Odense, Denmark).

\section{Results}

A total of 238 patients were invited to enter the study. Of these, 24 patients declined the invitation, 16 did not meet inclusion criteria, and an additional 8 were excluded due to non-response (Figure 1). Therefore, 382 questionnaires

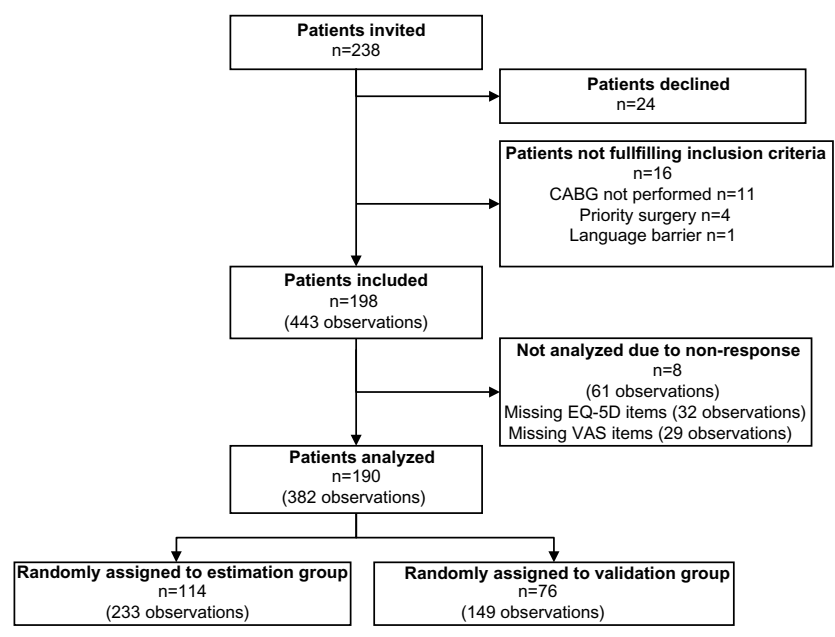

Figure I Flowchart describing the inclusion of patients.

Abbreviations: $n$, number; CABG, coronary artery bypass grafting; EQ-5D, EuroQol 5 Dimensions questionnaire; VAS, visual analog scale. from 190 patients were analyzed in the study. Because only patients seen at the outpatient clinic at Aalborg University Hospital filled out the third questionnaire, only 55 patients answered all three questionnaires. The baseline and intraoperative characteristics of the patients are shown in Table 1. No differences in patient characteristics were observed between the estimation dataset and validation dataset.

Figure 2 shows the five VAS items and the phrases used at both ends of the scale. The mean utility and VAS scores are reported in Table 2. The number of patients rating themselves in full health was somewhat limited, with observed utility scores ranging from -0.495 to 1 (Figure 3 ).

The first mapping model included age, sex, and the five VAS scores measuring health (GLS 1 in Table 3). Although the functional form of the explanatory variables was restricted to the additive level, the model explained approximately $63 \%$ of the variation in the EQ-5D utility score. In the second random effects GLS mapping model (GLS 2), the quadratic terms of the five VAS scores measuring health were added. Comparing the MAE and the RMSE between the two random effects GLS models, we found that the GLS 2 mapping model yielded the best fit to the estimation sample. Approximately $65 \%$ of the variation in EQ-5D utility scores was explained by the GLS 2 mapping model. The variables used in the GLS 2 model were also used to fit mapping models using random effects Tobit and CLAD regressions. The random effects Tobit mapping model was inferior to the GLS 2 mapping model, as it yielded higher MAE and RMSE values. The CLAD mapping model had a slightly lower MAE and a higher RMSE than the GLS 2 mapping-model had. In general, the mapping models performed better at higher observed EQ-5D utility scores (Table 4). In Figure 4 it can be seen that the reduction in performance in more severe health states is due to an over prediction of the EQ-5D utility score.

Bland-Altman plots of agreement between observed and predicted values of EQ-5D utility scores for the GLS 2 model are shown in Figure 5. Figure 5A shows agreement in the estimation sample and Figure 5B shows agreement in the validation sample. In both samples, the mapping-model

Table I Patients' baseline and intraoperative characteristics

\begin{tabular}{llll}
\hline Variable & $\begin{array}{l}\text { Estimation } \\
\text { sample } \\
\text { n=I I 4 }\end{array}$ & $\begin{array}{l}\text { Validation } \\
\text { sample } \\
\mathbf{n = 7 6}\end{array}$ & P-value \\
\hline Age (years), mean \pm SD & $68.4 \pm 9.2$ & $65.9 \pm 9.6$ & 0.07 \\
Female, n (\%) & $25(21.9)$ & $13(17.1)$ & 0.42 \\
Redo cardiac surgery, n (\%) & $2(1.8)$ & $0(0)$ & 0.52 \\
Concomitant surgery, n (\%) & $20(17.5)$ & $18(23.7)$ & 0.30 \\
\hline
\end{tabular}

Abbreviations: $n$, number; $S D$, standard deviation. 


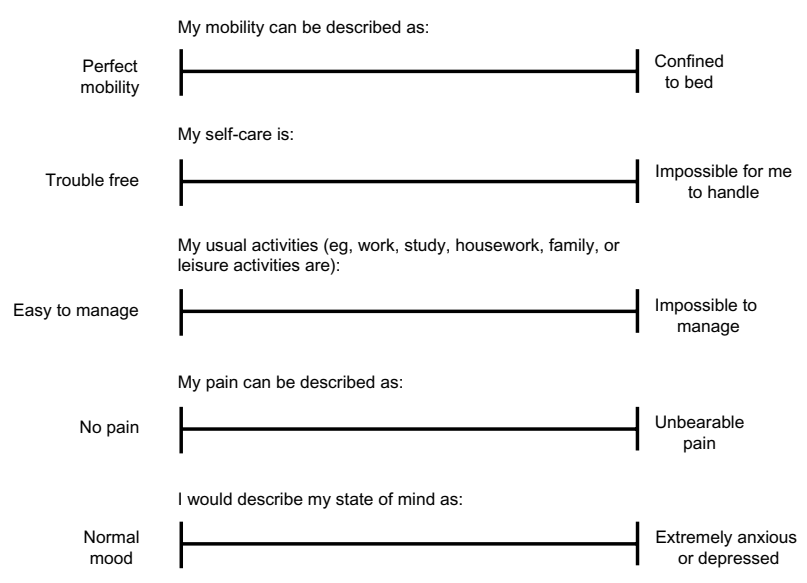

Figure 2 Questionnaire used to assess health on visual analog scales.

overestimated the EQ-5D utility scores for patients with low observed EQ-5D utility scores. The Bland-Altman 95\% limits of agreement from the validation sample $(-0.212$, 0.240 ) were similar to those from the estimation sample $(-0.233,0.232)$. A slight bias of 0.014 was observed in the validation sample.

\section{Discussion}

The GLS 2 mapping-model showed promising ability to predict mean utility scores. Our findings indicate that VAS scores for mobility, self-care, usual activity, pain, and mood could be used for obtaining estimates of utility among

Table 2 Mean utility and VAS scores for all observations

\begin{tabular}{|c|c|c|c|}
\hline Variable & $\begin{array}{l}\text { Estimation } \\
\text { sample } \\
(233 \\
\text { observations) }\end{array}$ & $\begin{array}{l}\text { Validation } \\
\text { sample } \\
\text { (149 } \\
\text { observations) }\end{array}$ & $P$-value \\
\hline $\begin{array}{l}\text { EQ-5D utility score, } \\
\text { mean } \pm S D\end{array}$ & $0.72 \pm 0.20$ & $0.73 \pm 0.16$ & 0.39 \\
\hline $\begin{array}{l}\text { VAS mobility }(\mathrm{mm}) \\
\text { mean } \pm \text { SD }\end{array}$ & $26.8 \pm 22.4$ & $26.6 \pm 20.3$ & 0.91 \\
\hline $\begin{array}{l}\text { VAS self-care }(\mathrm{mm}) \text {, } \\
\text { mean } \pm \mathrm{SD}\end{array}$ & $15.5 \pm 21.9$ & $|5.2 \pm 2| .5$ & 0.89 \\
\hline $\begin{array}{l}\text { VAS usual activity }(\mathrm{mm}) \\
\text { mean } \pm \text { SD }\end{array}$ & $44.4 \pm 32.7$ & $41.8 \pm 29.9$ & 0.43 \\
\hline $\begin{array}{l}\text { VAS pain }(\mathrm{mm}) \\
\text { mean } \pm S D\end{array}$ & $22.8 \pm 20.6$ & $23.8 \pm 22.1$ & 0.65 \\
\hline $\begin{array}{l}\text { VAS anxiety and } \\
\text { depression }(\mathrm{mm}) \\
\text { mean } \pm \text { SD }\end{array}$ & $16.3 \pm 20.6$ & $\mid 8.2 \pm 21.2$ & 0.39 \\
\hline Disease stage proxy & & & 0.87 \\
\hline Preoperative, n (\%) & $97(41.6)$ & $66(44.3)$ & \\
\hline $\begin{array}{l}\text { Postoperative day } 5, \\
\mathrm{n}(\%)\end{array}$ & $78(33.5)$ & $47(3 \mid .5)$ & \\
\hline $\begin{array}{l}\text { Postoperative day } 40, \\
\mathrm{n}(\%)\end{array}$ & $58(24.9)$ & $36(24.2)$ & \\
\hline
\end{tabular}

Abbreviations: EQ-5D, EuroQol 5 Dimensions questionnaire; SD, standard deviation; VAS, visual analog scale; $n$, number.

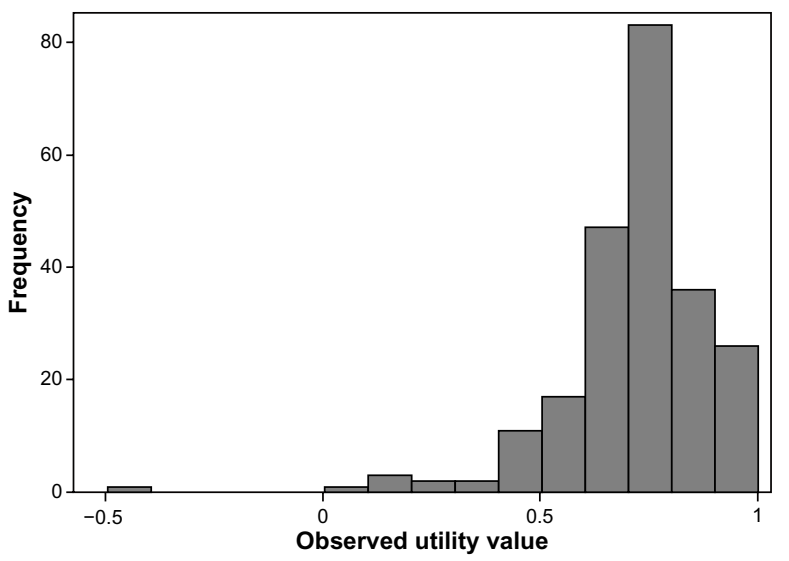

Figure 3 Observed EQ-5D utility scores in the complete dataset. Abbreviaton: EQ-5D, EuroQol 5 Dimensions questionnaire.

Table 3 Results of the estimated mapping-models

\begin{tabular}{|c|c|c|c|c|}
\hline \multirow[t]{2}{*}{ Parameter } & \multicolumn{4}{|c|}{ Random effects } \\
\hline & $\begin{array}{l}\text { GLS I } \\
\beta \text { (SE) }\end{array}$ & $\begin{array}{l}\text { GLS } 2 \\
\beta \text { (SE) }\end{array}$ & $\begin{array}{l}\text { Tobit } \\
\beta \text { (SE) }\end{array}$ & $\begin{array}{l}\text { CLAD } \\
\beta \text { (SE) }\end{array}$ \\
\hline Age & $\begin{array}{l}0.000259 \\
(0.00101)\end{array}$ & $\begin{array}{l}0.000255 \\
(0.00102)\end{array}$ & $\begin{array}{l}0.000599 \\
(0.00106)\end{array}$ & $\begin{array}{l}0.00198^{\ddagger} \\
(0.000206)\end{array}$ \\
\hline Female & $\begin{array}{l}-0.00263 \\
(0.0218)\end{array}$ & $\begin{array}{l}-0.0035 \mathrm{I} \\
(0.0220)\end{array}$ & $\begin{array}{l}-0.00898 \\
(0.0227)\end{array}$ & $\begin{array}{l}-0.0165^{\ddagger} \\
(0.00464)\end{array}$ \\
\hline \multicolumn{5}{|l|}{$\begin{array}{l}\text { VAS scores } \\
\text { for }\end{array}$} \\
\hline Mobility & $\begin{array}{l}-0.00177^{\dagger} \\
(0.000582)\end{array}$ & $\begin{array}{l}0.0000882 \\
(0.00128)\end{array}$ & $\begin{array}{l}-0.000198 \\
(0.00140)\end{array}$ & $\begin{array}{l}-0.00227^{\ddagger} \\
(0.000261)\end{array}$ \\
\hline Self-care & $\begin{array}{l}-0.000934 \\
(0.000548)\end{array}$ & $\begin{array}{l}-0.00204 \\
(0.00135)\end{array}$ & $\begin{array}{l}-0.00208 \\
(0.00146)\end{array}$ & $\begin{array}{l}-0.00405^{\ddagger} \\
(0.000309)\end{array}$ \\
\hline Usual activity & $\begin{array}{l}-0.00146^{\ddagger} \\
(0.000323)\end{array}$ & $\begin{array}{r}-0.00146 \\
(0.00111)\end{array}$ & $\begin{array}{l}-0.00204 \\
(0.00121)\end{array}$ & $\begin{array}{l}0.000328 \\
(0.000232)\end{array}$ \\
\hline Pain & $\begin{array}{l}-0.00158^{\dagger} \\
(0.000543)\end{array}$ & $\begin{array}{l}-0.00120 \\
(0.00136)\end{array}$ & $\begin{array}{l}-0.00213 \\
(0.00146)\end{array}$ & $\begin{array}{l}-0.000580^{*} \\
(0.000274)\end{array}$ \\
\hline $\begin{array}{l}\text { Anxiety and } \\
\text { depression }\end{array}$ & $\begin{array}{l}-0.00279 \ddagger \\
(0.000468)\end{array}$ & $\begin{array}{l}0.000335 \\
(0.00118)\end{array}$ & $\begin{array}{l}0.000236 \\
(0.00128)\end{array}$ & $\begin{array}{l}-0.00280^{\ddagger} \\
(0.000282)\end{array}$ \\
\hline \multicolumn{5}{|l|}{ Squared VAS } \\
\hline Mobility & & $\begin{array}{l}-0.0000255 \\
(0.0000163)\end{array}$ & $\begin{array}{l}-0.0000235 \\
(0.0000177)\end{array}$ & $\begin{array}{l}0.00001 \mathrm{I}^{\dagger} \\
(0.0000034)\end{array}$ \\
\hline Self-care & & $\begin{array}{l}0.0000165 \\
(0.000017 \mid)\end{array}$ & $\begin{array}{l}0.0000166 \\
(0.0000185)\end{array}$ & $\begin{array}{l}-0.0000429 \ddagger \\
(0.0000030)\end{array}$ \\
\hline Usual activity & & $\begin{array}{l}-0.0000008 \\
(0.0000105)\end{array}$ & $\begin{array}{l}0.0000037 \\
(0.0000115)\end{array}$ & $\begin{array}{l}-0.0000136^{\ddagger} \\
(0.0000022)\end{array}$ \\
\hline Pain & & $\begin{array}{l}-0.0000069 \\
(0.0000205)\end{array}$ & $\begin{array}{l}0.0000049 \\
(0.0000222)\end{array}$ & $\begin{array}{l}0.0000105^{*} \\
(0.0000043)\end{array}$ \\
\hline $\begin{array}{l}\text { Anxiety and } \\
\text { depression }\end{array}$ & & $\begin{array}{l}-0.0000445^{\dagger} \\
(0.0000161)\end{array}$ & $\begin{array}{l}-0.0000442^{*} \\
(0.0000175)\end{array}$ & $\begin{array}{l}0.0000105^{\dagger} \\
(0.0000038)\end{array}$ \\
\hline Constant & $\begin{array}{l}0.909^{\ddagger} \\
(0.0691)\end{array}$ & $\begin{array}{l}0.877^{\ddagger} \\
(0.0721)\end{array}$ & $\begin{array}{l}0.892^{\ddagger} \\
(0.0753)\end{array}$ & $\begin{array}{l}0.738^{\ddagger} \\
(0.0140)\end{array}$ \\
\hline Overall & 0.632 & 0.652 & & \\
\hline \multicolumn{5}{|l|}{ R-squared } \\
\hline MAE & 0.0857 & 0.0838 & $0.087 \mid$ & 0.0818 \\
\hline RMSE & 0.121 & 0.119 & 0.120 & $0.14 \mid$ \\
\hline
\end{tabular}

Notes: $* P<0.05 ;+P<0.01 ; \neq P<0.001$.

Abbreviations: GLS, generalized least squares; CLAD, censored least absolute deviation; SE, standard error; VAS, visual analog scale; MAE, mean absolute error; RMSE, root mean squared error. 
Table 4 Mean absolute error of mapping-models at subsets of observed EQ-5D utility scores

\begin{tabular}{lllll}
\hline Utility subset & GLS I & GLS 2 & Tobit & CLAD \\
\hline Utility $<0$ & 0.601 & 0.526 & 0.527 & 0.796 \\
$0 \geq$ utility $<0.25$ & 0.216 & 0.179 & 0.175 & 0.376 \\
$0.25 \geq$ utility $<0.5$ & 0.123 & 0.122 & 0.124 & 0.106 \\
$0.5 \geq$ utility $<0.75$ & 0.074 & 0.078 & 0.082 & 0.054 \\
$0.75 \geq$ utility $\leq 1$ & 0.074 & 0.071 & 0.074 & 0.072 \\
\hline
\end{tabular}

Abbreviations: EQ-5D, EuroQol 5 Dimensions questionnaire; GLS, generalized least squares; CLAD, censored least absolute deviation.

patients with cardiovascular disease. As much as $65 \%$ of the variability in utility scores could be explained, which is quite high compared with existing mapping models. ${ }^{3}$ Goldsmith et al predicted EQ-5D utility scores in a group of patients with coronary artery disease using demographic and clinical outcome variables and explained $48 \%-49 \%$ of the variability in utility scores and found RMSE and MAE to be 0.170 and 0.122 , respectively..$^{19}$ Longworth et al developed a model to map EQ-5D utility scores from clinical indicators for patients with stable angina and were able to explain $37 \%$ of the variation and showed an RMSE of $0.4764(\mathrm{RMSE}=\sqrt{ }$ Mean Squared Error $=\sqrt{ } 0.227) .{ }^{20}$ Our mapping-model may therefore be viewed as a reasonable method for mapping VAS scores to EQ-5D utility scores.

To illustrate the use of the GLS 2 mapping-model, imagine a comparison of a new, less-invasive surgical method with the conventional open surgical method in a health economic evaluation. The new surgical method reduced pain measured on a VAS scale by $10 \mathrm{~mm}$, from $40 \mathrm{~mm}$ to $30 \mathrm{~mm}$. For simplicity, assume that all other health outcomes are unchanged. The GLS 2 mapping-model is then applied to map the partial

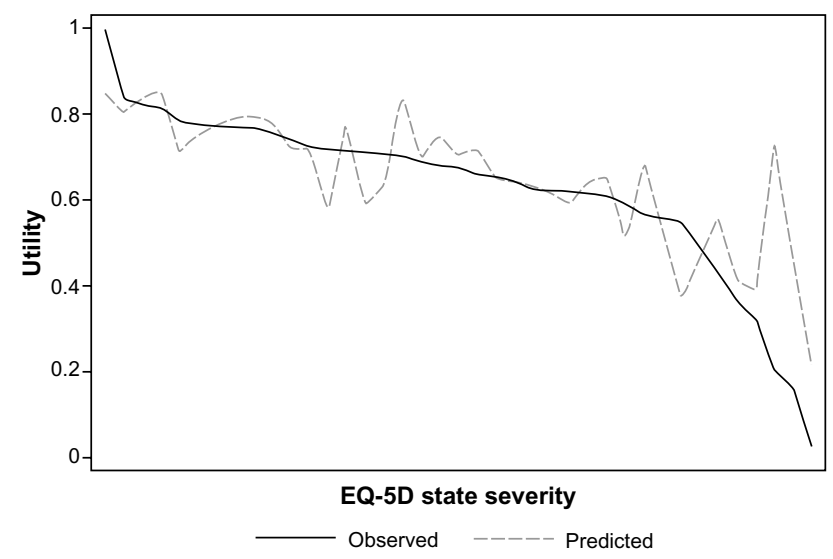

Figure 4 Mean observed and predicted EQ-5D utility scores in the validation sample.

Notes: The graph shows the agreement between the observed EQ-5D utility score and the mean of the predicted score. The observed health states are ordered on the $x$-axis according to their severity as valued by the Danish time trade-off tool. Abbreviation: EQ-5D, EuroQol 5 Dimensions questionnaire. effect of reducing patients' pain, under the ceteris paribus assumption, ie, holding all other factors fixed:

$$
\begin{aligned}
\text { Utility gain }= & \left(\beta_{\text {pain }} * \mathrm{VAS}_{\text {new }}+\beta_{\text {pain squared }} * \mathrm{VAS}_{\text {new }}{ }^{2}\right) \\
& -\left(\beta_{\text {pain }} * \mathrm{VAS}_{\text {conventional }}{ }^{2}\right) \\
& \left.+\beta_{\text {pain squared }} * \mathrm{VAS}_{\text {conventional }}\right)
\end{aligned}
$$

Utility gain $=\left(-0.00120 * 30-0.0000069 * 30^{2}\right)$

$$
-\left(-0.00120 * 40-0.0000069 * 40^{2}\right)
$$

Utility gain $=(-0.0422)-(-0.0590)=0.0168$

In this example, it was estimated that a $10 \mathrm{~mm}$ reduction in pain measured on a VAS, from an average of $40 \mathrm{~mm}$ to an average of $30 \mathrm{~mm}$, would increase patients' utility with 0.0168. Because the GLS 2 mapping-model contains squared terms, the utility gain from a $10 \mathrm{~mm}$ reduction on a VAS of pain depends on the severity of the pain, ie, the utility gain from a reduction in pain from $40 \mathrm{~mm}$ to $30 \mathrm{~mm}$ is not the same as from $60 \mathrm{~mm}$ to $50 \mathrm{~mm}$. If the GLS 1 mapping model had been used, a $10 \mathrm{~mm}$ reduction on a VAS of pain would yield the same utility-gain regardless of the initial level of pain. The uncertainty in the estimated utility gain could be modeled using the standard errors of the coefficients from the mapping model in a probabilistic sensitivity analysis.

\section{Strengths and limitations}

Because we treated all measurements as independent observations, the observed utility scores covered a wide range, especially because patients temporarily felt worse 5 days after CABG. Naturally, this approach increases the sample size somewhat artificially, and the standard errors presented in Table 3 should therefore only be used to estimate approximate confidence intervals. However, by using each measurement as independent we ensured that the mapping model is valid for all stages of the illness. The wide range of VAS scores and utility scores also enabled us to assess the GLS 2 mapping model's predictive ability at a subset of observed utility scores. This analysis showed that the reliability of our predictions declined as observed values decreased. This is a frequent limitation of mapping-models; ; ${ }^{3,11,19}$ however, it implies that the mapping models presented in this study may have a limited ability to predict utility scores for more severe conditions. Users of the mapping model should therefore be cautious when applying it in populations with large numbers of patients in poorer health. In such situations, alternative methods should be considered. The poor performance of the mapping model in patients with a more severe health condition is likely caused by a combination 
A

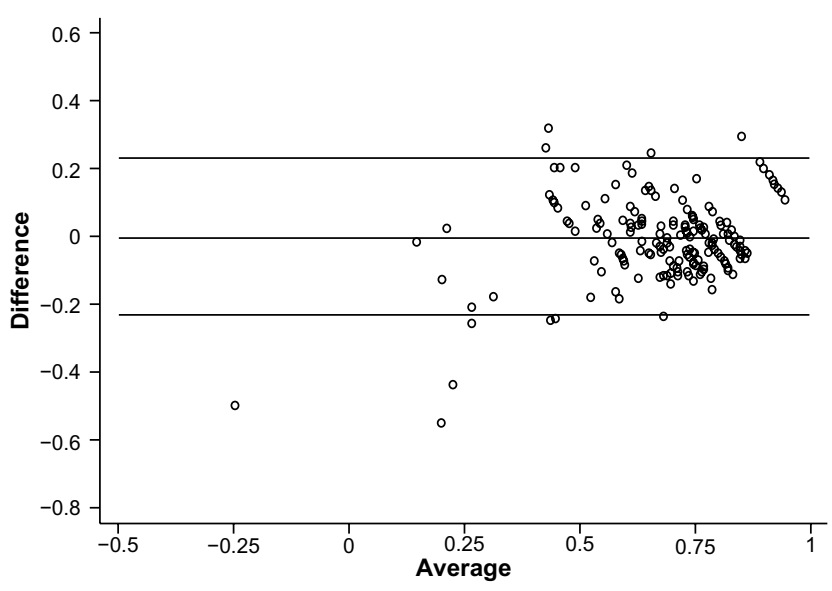

\section{B}

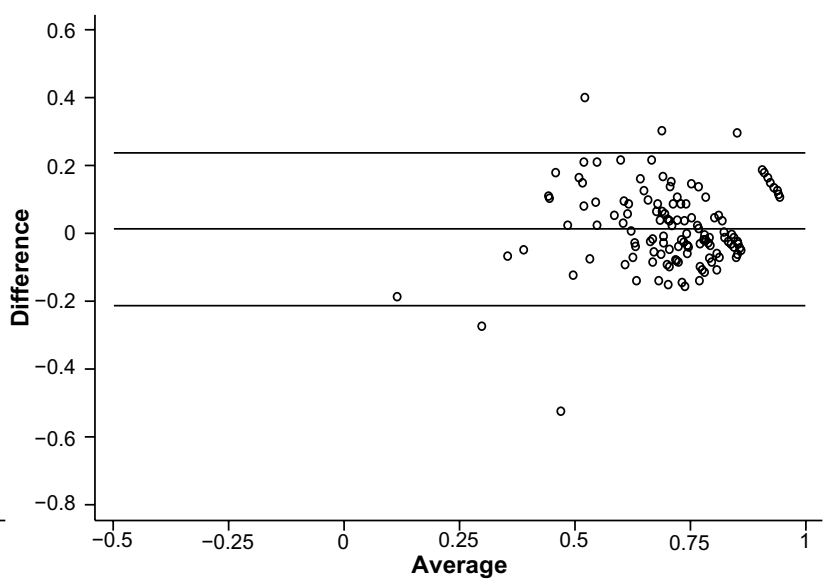

Figure 5 Bland-Altman plots of agreement between observed and predicted EQ-5D utility scores.

Notes: (A) Agreement in the estimation sample. (B) Agreement in the validation sample. The $\mathrm{x}$-axis depicts the mean of the observed value and the predicted value, and the $y$-axis shows the difference (observed minus predicted). The lines show the mean difference, ie, the estimated bias, and the $95 \%$ limits of agreement ( \pm I.96 SD of the mean difference).

Abbreviations: EQ-5D, EuroQol 5 Dimensions questionnaire; SD, standard deviation.

of the following: 1) the low number of patients with a low EQ-5D utility score in our dataset; 2) our exclusion of interaction terms and other covariates to ensure the mapping model could be used if researchers only had one of the five VAS measures; or 3) a larger intersubject variation in the use of the VAS scales for more severe conditions. The latter is supported by the fact that severe pain measured on a 11-point numeric rating scale could be from seven and upwards for some patients, while severe pain measured on a $100 \mathrm{~mm}$ VAS could be from $35 \mathrm{~mm}$ and upwards for others. ${ }^{6}$ In another study, the over-prediction of EQ-5D utility scores was shown to be worsened by the N3-term, which is added if severe problems were reported in at least one dimension. ${ }^{11}$ However, the Danish time trade-off values for EQ-5D do not contain such a jump and therefore the N3 term cannot be contributing to the over prediction among the severely ill in our analyses. ${ }^{9}$

The mapping models presented in this study were fitted using patients undergoing cardiac surgery. Cost-effectiveness analyses within this disease area have previously mapped health outcomes measured on VAS scales to utility scores. ${ }^{21,22}$ However, such attempts have also been made in other disease areas. ${ }^{23}$ Therefore, future work might include validating the mapping model for different patient groups and assessing the performance of an independent sample.

\section{Conclusion}

We conclude that it is possible to predict utility scores from VAS scores of the five dimensions of health used in the
EuroQol questionnaires. However, the predictive power decreased as observed utility scores declined. The use of the mapping model may therefore be inappropriate in more severe conditions.

\section{Acknowledgments}

The authors wish to thank Janni Stougaard Larsen, Hanne Lise Jespersen, Hanne Hoejland, Mette Stenstrop, and Birgitte Annette Wested for their assistance with the data collection.

\section{Author contributions}

All authors made substantial contributions to data generation and analysis, drafting or critical revision of the manuscript, and approval for the final version to be published.

\section{Disclosure}

The authors report no conflicts of interest in this work.

\section{References}

1. National Institute for Health and Care Excellence (NICE). Guide to the Methods of Technology Appraisal 2013. London, UK: NICE; 2013; Available from: http://www.nice.org.uk/media/D45/1E/GuideToMethodsTechnologyAppraisal2013.pdf. Accessed October 12, 2013.

2. Drummond MF, Sculpher MJ, Torrance GW, O’Brien BJ, Stoddart GL, editors. Methods for the Economic Evaluation of Health Care Programmes. 3rd ed. New York, NY: Oxford University Press; 2005.

3. Brazier JE, Yang Y, Tsuchiya A, Rowen DL. A review of studies mapping (or cross walking) non-preference based measures of health to generic preference-based measures. Eur J Health Econ. 2010;11(2): 215-225.

4. Tosh JC, Longworth LJ, George E. Utility values in National Institute for Health and Clinical Excellence (NICE) Technology Appraisals. Value Health. 2011;14(1):102-109. 
5. Hjermstad MJ, Fayers PM, Haugen DF, et al; European Palliative Care Research Collaborative (EPCRC). Studies comparing Numerical Rating Scales, Verbal Rating Scales, and Visual Analogue Scales for assessment of pain intensity in adults: a systematic literature review. J Pain Symptom Manage. 2011;41(6):1073-1093.

6. Williamson A, Hoggart B. Pain: a review of three commonly used pain rating scales. J Clin Nurs. 2005;14(7):798-804.

7. McDowell I. Measuring Health: A Guide to Rating Scales and Questionnaires. 3rd ed. New York, NY: Oxford University Press; 2006.

8. Kiaii B, Moon BC, Massel D, et al. A prospective randomized trial of endoscopic versus conventional harvesting of the saphenous vein in coronary artery bypass surgery. JThorac Cardiovasc Surg. 2002;123(2): 204-212.

9. Wittrup-Jensen KU, Lauridsen J, Gudex C, Pedersen KM. Generation of a Danish TTO value set for EQ-5D health states. Scand J Public Health. 2009;37(5):459-466.

10. Brazier J, Usherwood T, Harper R, Thomas K. Deriving a preferencebased single index from the UK SF-36 Health Survey. J Clin Epidemiol. 1998;51(11):1115-1128.

11. Rowen D, Brazier J, Roberts J. Mapping SF-36 onto the EQ-5D index: how reliable is the relationship? Health Qual Life Outcomes. 2009;7:27.

12. Feeny D, Furlong W, Torrance GW, et al. Multiattribute and singleattribute utility functions for the health utilities index mark 3 system. Med Care. 2002;40(2):113-128.

13. Longworth L, Rowen D. Mapping to obtain EQ-5D utility values for use in NICE health technology assessments. Value Health. 2013;16(1):202-210.

14. Sullivan PW. Are utilities bounded at 1.0? Implications for statistical analysis and scale development. Med Decis Making. 2011;31(6): 787-789.
15. Pullenayegum EM, Tarride JE, Xie F, O'Reilly D. Calculating utility decrements associated with an adverse event: marginal Tobit and CLAD coefficients should be used with caution. Med Decis Making. 2011;31(6):790-799.

16. Sullivan PW, Ghushchyan V. Mapping the EQ-5D index from the SF-12: US general population preferences in a nationally representative sample. Med Decis Making. 2006;26(4):401-409.

17. Powell JL. Least absolute deviations estimation for the censored regression model. J Econom. 1984;25(3):303-325.

18. Jolliffe D, Krushelnytskyy B, Semykina A. Censored least absolute deviations estimator: CLAD. Stata J. 2000;10(58):13-16.

19. Goldsmith KA, Dyer MT, Buxton MJ, Sharples LD. Mapping of the EQ-5D index from clinical outcome measures and demographic variables in patients with coronary heart disease. Health Qual Life Outcomes. 2010;8:54.

20. Longworth L, Buxton MJ, Sculpher M, Smith DH. Estimating utility data from clinical indicators for patients with stable angina. Eur $J$ Health Econ. 2005;6(4):347-353.

21. Rao C, Aziz O, Deeba S, et al. Is minimally invasive harvesting of the great saphenous vein for coronary artery bypass surgery a cost-effective technique? J Thorac Cardiovasc Surg. 2008;135(4):809-815.

22. Oddershede L, Andreasen JJ, Brocki BC, Ehlers L. Economic evaluation of endoscopic versus open vein harvest for coronary artery bypass grafting. Ann Thorac Surg. 2012;93(4):1174-1180.

23. Oddershede L, Petersen SS, Kristensen AK, Pedersen JF, Rees SE, Ehlers L. The cost-effectiveness of venous-converted acid-base and blood gas status in pulmonary medical departments. Clinicoecon Outcomes Res. 2011;3:1-7.
ClinicoEconomics and Outcomes Research

\section{Publish your work in this journal}

ClinicoEconomics \& Outcomes Research is an international, peerreviewed open-access journal focusing on Health Technology Assessment, Pharmacoeconomics and Outcomes Research in the areas of diagnosis, medical devices, and clinical, surgical and pharmacological intervention. The economic impact of health policy and health systems

\section{Dovepress}

organization also constitute important areas of coverage. The manuscript management system is completely online and includes a very quick and fair peer-review system, which is all easy to use. Visit http://www.dovepress.com/testimonials.php to read real quotes from published authors. 